\title{
ANPEd e Intercom: panorama da produção dos pesquisadores em Educação e Comunicação na última década
} ANPEd and Intercom: an overview of the production of researchers in education and communication in the last decade

\author{
Lígia Beatriz Carvalho de Almeida \\ Doutoranda em Educação (Unesp Marília) e docente da Univ. do Sagrado Coração \\ ligiabeatrizcarvalho@ig.com.br \\ Margareth Cavalcante de Castro Lobato
}

Doutoranda em Educação (Unesp-Marília) e docente da Universidade Federal de Goiás mclobato@gmail.com

Samir Mustapha Ghaziri

Doutorando em Educação (Unesp-Marília)

samirghaziri@yahoo.com.br

\section{Resumo:}

$\mathrm{O}$ artigo expóe resultados parciais de pesquisa que investiga características das propostas voltadas ao tema educação formal e comunicação, a partir dos artigos publicados entre os anos de 2000 e 2010, nos anais dos grupos de pesquisa sobre Educação e Comunicação ligados à ANPEd e à Intercom. O estudo identificou convergência quanto aos pressupostos teóricos, concepçóes sobre a instituição escolar e propostas para a educação formal, fatores que ajudam a consolidar um campo de saber específico.

Palavras-chave: Educomunicação; ANPEd; Intercom

\section{Abstract:}

This paper presents the partial results of a research that investigated the characteristics of proposals concerning formal education and communication found in articles published between 2000 and 2010, in the proceedings of research groups on Education and Communication linked to ANPEd and Intercom. The study identified the convergence between the groups concerning theoretical perspectives, conceptions of school system and their proposals for formal education, factors that help to consolidate a specific field of knowledge.

Keywords: Educommunication; ANPEd; Intercom 
Bte texto descreve propostas de educação para a mídia ou de uso de tec-

- nologias midiáticas voltadas à escola básica, formuladas por pesquisadores dos campos da educaçáo e da comunicação, a partir das reuniôes anuais da Associação Nacional de Pós-Graduação e Pesquisa em Educação (ANPEd) e da Sociedade Brasileira de Estudos Interdisciplinares da Comunicação (Intercom) .

O termo mídia designa os sistemas de comunicação mediada por aparatos tecnológicos, geridos por pessoas jurídicas em sua maioria, inseridos na dinâmica da indústria cultural da informação e entretenimento. Tais sistemas colocam seus produtos em circulação na esfera pública de comunicação, caso do rádio, da televisão, do cinema, do jornal, da revista, entre outros, permitindo o acesso simultâneo de múltiplos receptores. O termo em questão abarca ainda a comunicação disponibilizada em plataformas como a internet, quando emissor e receptor são substituídos pelo termo usuário, face à possibilidade de atuação dos sujeitos, ora como receptores ora como transmissores de mensagens.

Mostafa e Maximo (2003) realizaram minucioso levantamento sobre a produção dos dois grupos em questão, entre os anos de 1994 e 2001. Os pesquisadores buscaram os autores mais recorrentes e as tendências epistemológicas dessa produção científica, concluindo que:

Em ambas as associaçôes científicas, a análise da cultura se coloca como a principal mediação na constituição do campo. Porém, a compreensão da cultura para os pesquisadores que se apresentam na Intercom está mais próxima da tradição dos estudos de recepção da América Latina, enquanto os pesquisadores que se apresentam na ANPEd aproximam-se mais dos estudos culturais via Hall ou Giroux, ambos com alta pontuaçáo, sem esquecer Foucault como uma espécie de matriz teórica nas análises da "materialidade discursiva" das linguagens. Poderíamos falar, talvez, em um marxismo crítico gramsciano na Intercom e em um pós-marxismo (pós-estruturalismo) na ANPEd. Se tivéssemos de estender as classificações, diríamos que na ANPEd o pós-marxismo pede passagem em meio a um marxismo crítico, com a presença de Canclini, e um mais tradicional, reprodutivista e forte na presença de Adorno. [...] No interior de cada uma das associaçóes científicas, há uma espécie de diversificação de discursos em cuja repartição pode-se notar três conjuntos de famílias discursivas referidas ao mesmo campo discursivo da comunicação e educação: humanismo (por exemplo, Soares, Penteado, Porto ou Moran), criticismo (trazido pelos homens das mediaçóes da Intercom) e pós-criticismo (Silva, Louro, Fischer, Veiga-Neto ou Costa, por exemplo). (MOSTAFA; MÁXIMO, 2003: 100-1)

$\mathrm{Na}$ presente pesquisa, observa-se que o quadro apresentado por aqueles autores se mantém no período analisado, demonstrando consolidação do campo de saber e de seu referencial teórico. Permanece atual a constataçáo de que o legado do educador Paulo Freire figura entre as linhas mestras para ambos os grupos 
de pesquisa, evidenciando tendência de adoção de práticas para a resistência e a autonomia que permitam viabilizar o papel social, cultural e político da educação e da comunicação. (MOSTAFA; MÁXIMO, 2003: 100)

Sobre a ANPEd, o pós-estruturalismo, tendência então dominante, manteve-se em evidência. Percebeu-se, contudo, incremento de citaçôes a Valente, Moran, Levy, Castells, Thompson, Bourdieu, Kenski, como reflexo da premência de se abordar a formação do professor para a educação a distância e a apropriação formal das novas tecnologias da informação e da comunicação (NTICs). Em relação à Intercom, os fundadores do grupo de pesquisa aqui analisado (Soares, Citelli e Baccega, da Escola de Comunicaçóes e Artes da Universidade de São Paulo - ECA/USP), que já figuravam em 2001 entre as principais referências da área, somados a Moran, Penteado, Pretto e Belloni (MOSTAFA e MAXIMO, 2003), continuam entre os mais mencionados.

Costa, em artigo de revisão publicado em 2009, também evidencia a influência do Núcleo de Comunicação e Educação da ECA/USP, nos trabalhos do grupo, e o emprego do termo educomunicação, que vem se tornando frequente em ambos os grupos:

\begin{abstract}
Em diferentes regióes do país, ressoam trabalhos sobre "educomunicação", uma terminologia criada para demarcar as interfaces educação/comunicação, fundamentos metodológicos, técnicos e estéticos, cujo propósito é o de estimular projetos e práticas de educação para mídia num sentido que lida tanto com a interpretação das linguagens quanto das açóes formativas com o uso dos meios. (COSTA, 2009: 156)
\end{abstract}

Continua válido em relação à Intercom o principal arcabouço teórico mencionado por Mostafa e Maximo: as teorias críticas da recepção e das mediações, apresentadas por pensadores latino-americanos como: "Martin-Barbero, Orozco, Canclini, Kaplun (com Freire integrando esse conjunto). [...] Especialmente Martin-Barbero, liderando o grupo". (MOSTAFA; MAXIMO, 2003: 99)

Em ambos os grupos há referências a teóricos norte-americanos e europeus (Inglaterra, França e Itália). Há diversas referências a Benjamin e Adorno, pósestruturalistas (Bourdieu, Foucault), sociólogos (Bauman, Perrenoud e Ianni), filósofos (Eco, Flusser, Baudrillard, McLuhan), historiadores (Chartier, De Certeau), antropólogos (Canclini, Lévi-Strauss). Bakhtin e Vygotsky são também nomes reiterados.

Em linhas gerais, recorre-se pouco a autores institucionais, como a UNESCO, a ONU, o núcleo da ECA, o que demonstra a dificuldade de articulação entre os pesquisadores da temática, tipificando uma fase ainda de empenho individual dos envolvidos.

\title{
Procedimentos metodológicos
}

As unidades de análise foram os artigos apresentados no GT Educação e Comunicação da ANPEd (GT/EC/ANPEd) e no GP Comunicação e Educação da Intercom (GP/CE/In), entre os anos de 2000 e 2010. Foram observados 510 artigos , sendo 215 do GT/EC/ANPEd e 295 do GP/CE/In.

Para a delimitação dos artigos, iniciou-se pela análise dos resumos e de pa- 
rágrafos introdutórios, dependendo do caso, passando-se, na sequência, à leitura na íntegra dos artigos que se referiam à educação básica formal, e às mídias e/ou tecnologias. A etapa seguinte envolveu a análise de conteúdo e classificação dos dados em categorias. Do total de 215 artigos do GT/EC/ANPEd, separaram-se 84 para análise detalhada de conteúdo. Entre os 295 da GP/CE/In, 114 serviram para a efetiva coleta de dados.

A diferença entre a estrutura formal do texto exigida em cada evento fez com que nem sempre fosse possível encontrar dados referentes às categorias de análise previamente delimitadas, apresentadas na sequência:

a) Autoria e procedência: origem e formação dos pesquisadores;

b) Perspectiva técnica ou midiática: os textos que tinham foco no uso da tecnologia foram considerados textos com "perspectiva técnica”. Quando o texto relatou a preocupação do pesquisador com o estudo da mídia, foi classificado como "perspectiva midiática";

c) Pesquisa aplicada ou teórica (básica): delimitaram-se os trabalhos com preocupação epistemológica e os que, de alguma maneira, observaram o cotidiano da escola ou desenvolveram atividades envolvendo docentes ou discentes. Indicou-se, em uma subcategoria, o percentual dessas atividades desenvolvidas em ambiente escolar;

d) Escopo: refere-se à temática central dos artigos, considerando que alguns assuntos são predominantes e foram organizados em torno de três eixos, considerados subcategorias: professor, alunos e escola. Deve-se, entretanto, atentar para o fato de que é uma opção por forma de organização da categoria em análise por predominância, e não uma delimitação rígida dos dados coletados, pois, em muitos casos, os eixos apresentam contatos, simultaneidades, os quais são observados separadamente e em conjunto, para melhor compreensão da temática.

\section{ANPED}

\section{Autoria e procedência dos pesquisadores}

Em linhas gerais, os trabalhos apresentados são de autoria coletiva, na combinação orientador-orientando, ou de professor pesquisador vinculado a grupos de pesquisa de instituiçáo de ensino superior, o que se revela consonante com o objetivo de fomento à produção científica e acadêmica da área educacional no país.

TABELA 1 - ORIGEM DOS TRABALHOS

\begin{tabular}{lccccccc} 
Região & Sul & Sudeste & Centro Oeste & Nordeste & Norte & Internacional & Total \\
Quant. de trabalhos & 28 & 37 & 8 & 6 & 2 & 2 & 84 \\
$\%$ & 34,6 & 44,6 & 9,6 & 7,14 & 2,3 & 2,3 & 100 \\
\hline Fonte: dados coletados pelos autores & & & &
\end{tabular}

A concentração dos trabalhos no sul e no sudeste do país (cerca de $80 \%$ do total) se explica e tende a permanecer por conta do regime de associação. Só 
participam do evento, sócios regulares da ANPEd, algo que acaba por incentivar a continuidade e menos a rotatividade entre os autores.

\section{Perspectiva técnica ou midiática}

TABELA 2 - PERSPECTIVA DA ABORdAgEM

$\begin{array}{lccc} & \text { Midiática } & \text { Técnica } & \text { Total } \\ \text { Quant. de trabalhos } & 62 & 22 & 84 \\ \% & 73,8 & 26,2 & 100\end{array}$

Fonte: dados coletados pelos autores

A tendência dominante é a perspectiva midiática, em que se concebe a educação como processo de comunicação. Destacam-se termos que remetem à idéia de interação, interlocução, integração, comunicação, socialização, participação, comunidades de aprendizagem e colaboração. Tanto nas pesquisas cujo foco era o professor, quanto naquelas centradas nos alunos, predominam propostas de conhecimento e o reconhecimento da mídia e TICs como fundamentais para a compreensão de seu uso na sociedade. Ainda assim, em boa parte destes $73,8 \%$ de trabalhos, observa-se a preocupação técnica, no sentido de apropriação do uso do aparato midiático e tecnológico. Nos demais $26,2 \%$ dos trabalhos, sobressai a perspectiva instrumental, de meio para o trabalho com conteúdos, no sentido de aprendizagem, apropriação, motivação, inovação, facilitação, ou acesso ao conhecimento.

\section{Pesquisa aplicada ou teórica}

TABELA 3 - NATUREZA dA PESQUisA

$\begin{array}{lccc} & \text { Pesquisa teórica } & \text { Pesquisa aplicada } & \text { Total } \\ \text { Quant. de trabalhos } & 30 & 54 & 84 \\ \% & 35,8 & 64,2 & 100\end{array}$

Fonte: dados coletados pelos autores

Observou-se maior quantidade de pesquisas teóricas e propositivas no início da década, predominando a ideia de que o desenvolvimento tecnológico exige a inserção da comunidade escolar na cultura digital e a integração de mídias e tecnologias ao cotidiano escolar. Posteriormente, constatou-se maior interesse por pesquisas aplicadas sobre experiências realizadas em escolas. Estes trabalhos tratam de estudo de campo sobre letramento e de letramento digital, da formação para a recepção e para a produção de sentido com uso de mídias, de metodologias de ensino ou de aprendizagem mediada por computador. Em menor quantidade, há trabalhos sobre apropriação do uso de recursos midiáticos e tecnológicos como instrumentos para a aprendizagem. Já no final da década, observou-se retomada de estudos teóricos propositivos, com temáticas mais voltadas para a informática, e menos para outras mídias.

\section{TABELA 4 - LOCAL DE DESENVOLVIMENTO DE ATIVIDADES}

$\begin{array}{lccc}\text { Local } & \text { Escola } & \text { Outro } & \text { Total } \\ \text { Quantidade de trabalhos } & 76 & 8 & 84 \\ \% & 90,4 & 9.6 & 100\end{array}$

Fonte: dados coletados pelos autores. 
Em relação aos estudos que se referem às atividades curriculares realizadas com alunos na escola, quase a totalidade ocorreu em sala de aula. Os demais espaços utilizados foram laboratórios de informática, sala de vídeo, espaços comuns como pátios, e, excepcionalmente, em um museu. Há pesquisas realizadas na ou sobre a escola básica, envolvendo uma ou mais de uma série e nível. No caso de pesquisas sobre formação continuada dos professores em exercício, os estudos ocorreram na sala de aula e/ou nos Núcleos de Tecnologias Educacionais - NTEs, das Secretarias de Educação.

\section{Escopo}

Quanto à temática central, os textos da ANPEd estão divididos entre os três eixos delimitados:

\section{TABELA 5 - ENFOQUe TEMÁTICO}

$\begin{array}{lcccc}\text { subcategoria } & \text { Professor } & \text { Aluno } & \text { Escola } & \text { Total } \\ \text { quantidade de trabalhos } & 32 & 37 & 15 & 84 \\ \% & 38,1 & 44,1 & 17,8 & 100\end{array}$

Em relação a mídias e o professor, os temas recorrentes referem-se influência da mídia na compreensão de mundo e na prática pedagógica do professor. Destacam-se as pesquisas que tratam da influência de programas de TV, de sites da internet e da leitura midiática. Sobressai, ainda, a necessidade de os professores usarem apropriadamente recursos como vídeo, TV, jornal, rádio e os recursos da informática, em sala de aula. Essa demanda se intensifica em função da aquisição de equipamentos multimídia nas escolas, pelo acesso dos professores tanto ao computador quanto à internet e pela disseminação do uso destes pelos alunos, direta e indiretamente, pressionando o professor para inseri-los em sua prática pedagógica. A demanda ocorreu também pela percepção do professor de uso mais contextualizado dos próprios meios, em sua dinâmica social, como parte do processo comunicativo na escola, bem como pela aquisiçáo de mídias e softwares educativos que permitem apresentar os conteúdos curriculares de forma mais atrativa ou por conta de alunos com necessidades especiais.

Há trabalhos que tratam da formação do professor da educação básica para o uso das NTIC. Optou-se por considerar as pesquisas em que essa formação é destinada aos professores da educação básica formal em exercício, visando ao seu uso na escola. Foram identificados estudos indicando que a orientação predominante refere-se ao uso integrado das mídias ao cotidiano do aluno, com orientaçôes para a adoçáo ou desenvolvimento de metodologias colaborativas entre os alunos. Tais trabalhos sempre se referem a como o desenvolvimento tecnológico dos recursos da internet possibilita cada vez mais a interatividade, como blogs, wiki, compartilhamento de conteúdo, além do uso dos Ambientes Virtuais de Aprendizagem (AVA) na educação presencial e na educação online.

Em relação ao eixo mídia e alunos, dos 44 trabalhos, 37\% referem-se à influência das mídias e das tecnologias sobre a formaçáo da visão de mundo do aluno, com reflexos na sua constituição enquanto sujeito ou nas suas formas de pensar e de agir. São programas de TV, filmes, músicas, jornais, livros, imagens digitais, e obras que fazem parte do cotidiano do aluno. Abordam ainda questóes 
sobre o letramento e sobre a influência da internet na escrita. Os estudos objetivam observar o perfil dessa influência ou visam ao trabalho do professor para a formação de senso crítico e capacidade de apreciação estética, com fundamento em estudos sobre recepção.

Os outros estudos são sobre a apropriação que o aluno faz da tecnologia para trabalhar conteúdos curriculares, transversais e midiáticos ou, com maior destaque, para retratar a sua realidade ou expressar a sua visão de mundo. Há também artigos que tratam do uso de meios como vídeo, rádio escolar, gravadores, computadores, máquinas fotográficas ou filmadoras, na perspectiva do letramento, ou com a finalidade de produçáo e divulgação de textos produzidos em diversas linguagens.

O terceiro eixo reúne 15 textos (17,8\%), que tratam das mídias e cultura escolar, sob o aspecto histórico de uso das mídias no ambiente escolar, ou na forma de estudo propositivo. Por fim, em menor grau, registram-se estudos sobre o uso de softwares para aprendizagem de conteúdos curriculares, ou sobre apropriação e uso das TIC no cotidiano escolar e social.

\section{INTERCOM}

Autoria e procedência dos pesquisadores

TABELA 6 - FORMAÇÃO DOS AUTORES (GRADUAÇÃO)

\begin{tabular}{lccccc} 
& Comunicação & Educação & Misto & Outros & Total Artigos \\
Áreas de formação & 59 & 43 & 10 & 2 & 114 \\
$\%$ & 51,7 & 36,8 & 8,7 & 1,7 & 100 \\
\hline
\end{tabular}

Fonte: dados coletados pelos autores.

Diferentemente do que ocorre na ANPEd, os trabalhos apresentados na Intercom possibilitaram verificar a formação dos autores. Considerou-se a formação em nível de graduação do conjunto de autores de cada trabalho. A maior parte dos participantes é da área de Comunicação Social, com pós-graduação em Educação. Entre os autores oriundos da área da Educação, muitos possuem pós-graduaçáo em Comunicação Social. Em alguns casos, observa-se a uniáo de autores das duas principais áreas de formação: educação e comunicação. Há, contudo, conjunto de autores com formação integral em educação ou comunicação, bem como de outras áreas como biblioteconomia, sociologia, filosofia, antropologia, design. Em muitos artigos, percebe-se a combinação orientador/orientando, evidenciando esforço dos programas de pós-graduação para a consolidação da pesquisa na área.

TABELA 7 - ORIGEM DOS TRABALHOS

$\begin{array}{lccccccc}\text { Região } & \text { Sul } & \text { Sudeste } & \text { Centro-Oeste } & \text { Nordeste } & \text { Norte } & \text { Internacional } & \text { Total } \\ \text { Quant. de trabalhos } & 23 & 63 & 6 & 15 & 5 & 2 & 114 \\ \% & 20,1 & 55,2 & 5,2 & 13,1 & 4,3 & 1,7 & 100\end{array}$

Fonte: dados coletados pelos autores

Tal como acontece na ANPEd, é evidente a concentração de autores provenientes das regióes sul e sudeste. Mesmo realizado de forma itinerante, sendo alocada em universidades de diferentes regiōes brasileiras, a Intercom reúne $75 \%$ de trabalhos oriundos do centro-sul do país. No caso da ANPEd, até 2011, as reuniōes foram rea- 
lizadas na regiáo sudeste (Minas Gerais). A única distinção evidente diz respeito à participação da região nordeste, significativamente maior na Intercom do que na ANPEd.

\section{Perspectiva técnica ou midiática}

TABELA 8 - PERSPECTIVA DA ABORDAGEM

\begin{tabular}{lccc} 
Perspectivas & Midiática & Técnica & Total \\
\hline Quantidade de trabalhos & 80 & 34 & 114 \\
$\%$ & 70,2 & 29,8 & 100
\end{tabular}

Fonte: dados coletados pelos autores

Em torno de 70,2\% dos trabalhos apresentam preocupação com viés midiático, contra 29,8\% que mantêm uma abordagem operacional da tecnologia. Nos anos de 2002 e 2009 registraram-se os maiores percentuais de interesse pela perspectiva técnica, com estudos abordando a informática na educação e a educação a distância $(\mathrm{EaD})$. Tal incremento, em 2002, pode ser decorrente da gradual implantaçáo, a partir de 1998, de laboratórios com computadores em escolas públicas de ensino básico de todo o Brasil, promovida pelo Programa Nacional de Informática na Educação (Proinfo) do Ministério da Educação (MEC) e a cobrança para que os docentes se preparassem para lidar com a tecnologia (BRASIL, 2011). No final da década, a elevação pode ser consequência da necessidade de formação de docentes e tutores para os programas de EaD que se multiplicam no país. Na ANPEd, $73,8 \%$ das publicaçôes tiveram abordagem predominantemente midiática, contra 26,2 com abordagem predominantemente técnica. Constatou-se igualmente o incremento de estudos sobre a apropriação da tecnologia como recurso de aprendizagem no final da década.

Pesquisa aplicada ou teórica

TABELA 9 - NATUREZA DA PESQUISA

$\begin{array}{lccc}\text { Natureza } & \text { Teórica } & \text { Aplicada } & \text { Total } \\ \text { Quantidade de trabalhos } & 54 & 60 & 114 \\ \% & 47,7 & 52,3 & 100\end{array}$

Fonte: dados coletados pelos autores.

O número de trabalhos aplicados foi discretamente maior que o de teóricos. Os estudos aplicados englobam pesquisas envolvendo docentes, ou crianças e jovens, em ambientes escolares e, até mesmo, fora da escola, mas que tinham como finalidade embasar práticas pedagógicas escolares. $\mathrm{O}$ volume de trabalhos com caráter puramente epistemológico é significante, quase $48 \%$ do total, o que revela comprometimento com construção das bases teóricas de um campo emergente. A diferença na ANPEd é mais relevante, onde o percentual de estudos teóricos é de $35,8 \%$ contra $64,2 \%$ de pesquisas aplicadas, evidenciando maior engajamento com a dinâmica da escola.

Local de desenvolvimento de atividades práticas 
TABELA 10 - LOCAL DE DESENVOLVIMENTO DE ATIVIDADES

$\begin{array}{lccc}\text { Local } & \text { Escola } & \text { Outro } & \text { Total } \\ \text { Quantidade de trabalhos } & 47 & 13 & 60 \\ \% & 78,3 & 21,7 & 100\end{array}$

Fonte: dados coletados pelos autores.

Dos estudos que relataram a aplicação de atividades práticas, 78,3\% usaram o espaço da educaçáo formal para a realização de atividades, os outros se desenvolveram em ambientes de educação não formal, como ONGs, associaçóes de bairro e instituições religiosas.

Em se tratando das propostas de educação para a mídia, percebe-se a relação entre a escolha do espaço para aplicação dessas atividades e a intenção da maioria dos pesquisadores de que elas sejam integradas às atividades curriculares na escola formal. Mesmo entre as pesquisas desenvolvidas em espaços de educação náo formal, constata-se a utilização desses locais para experiências educativas tendo, porém, o objetivo de subsidiar o planejamento de açóes em espaços de educação formal. É ínfima a parcela de trabalhos que se ocupa de atividades extracurriculares.

Escopo

TABELA 11 - ENFOQUe TEMÁTICO

$\begin{array}{lcccc}\text { subcategoria } & \text { Professor } & \text { Aluno } & \text { Escola } & \text { Total } \\ \text { Quantidade de trabalhos } & 41 & 48 & 25 & 114 \\ \% & 35,9 & 42,1 & 21,9 & 100\end{array}$

Fonte: dados coletados pelos autores

O esforço e as limitaçóes ao trabalho docente são, na maior parte das vezes, reconhecidos. É emblemático o diagnóstico feito por Citelli, que desenvolve pesquisas com grandes amostras de docentes. Segundo ele, os docentes não só se preocupam com os conteúdos, com o ajuste de sistemas retóricos e o domínio conceitual, mas se esforçam também para alcançar "os planos dos afetos, da compreensão, do entendimento das diferenças e dificuldades que marcam o universo dos alunos". (CITELLI, 2004: 7)

As pesquisas revelam, por um lado, boa vontade dos docentes e profissionais atentos para as novas linguagens da comunicação e, por outro, a dificuldade de se trabalhar com as mesmas na sala de aula. Afirma-se que a maior parte desses profissionais prioriza o uso de mídias prontas, confundindo recurso com veículo, ignorando o potencial de uso da mídia para interlocução. Fragilidades conceituais também são relacionadas, como, por exemplo, a não compreensão do conceito de mediaçóes, considerado fundamental para o entendimento das relaçóes entre os campos da Comunicação e Educação.

Contraditoriamente, há falta de sintonia entre os apelos por um docente mais preparado e o percentual de estudos que se ocuparam especificamente da formaçáo docente, como demonstra a tabela a seguir. 
TABELA 12 - PESQUISAS APLICADAS VISANDO A FORMAÇÃO DOCENTE

\begin{tabular}{|lccc|}
\hline & Formação Docente & Outros & Total \\
\hline Total de artigos & 28 & 86 & 114 \\
\hline$\%$ & 24,5 & 75,5 & 100 \\
\hline Fonte: dados coletados pelos autores & & &
\end{tabular}

Um pouco menos de um quarto dos estudos se ocupou da formação docente, abarcando a formaçáo inicial ou em serviço. Destaca-se neles, a necessidade de estar o docente preparado para o uso consciente do potencial pedagógico das TIC. Da mesma forma que se enaltece o potencial que a mídia e a tecnologia oferecem para a construção de redes de inteligência coletiva unindo as escolas, reconhece-se sua total dependência da mediação humana. $\mathrm{O}$ alerta é que o docente despreparado permitirá a incorporação das tecnologias e das mídias de forma acrítica, o que conduzirá apenas à reprodução de discurso ideologicamente modernizante sobre o ensino, levando ao deslocamento de significados e impedindo a transformação da informação em conhecimento. Nesse caso, a comunicação se reduziria a mera circulação de informaçôes entre grupos que compartilham os mesmos recursos de aprendizagem, mas não os mesmos interesses, produzindo apenas relações de instantaneidade, impedindo a formação dos elos das redes.

Em outro subgrupo, o aluno é objeto de investigaçóes que procuram conhecer o uso que faz da tecnologia e da mídia, por se considerar que ele sofre a influência da mídia e é seduzido pela tecnologia. Acredita-se que ao compreender a dinâmica de atuação das indústrias da mídia e da tecnologia na sociedade, será capaz de utilizá-las na construção de uma realidade melhor. Sua condição atual é de sujeito passivo e refém de uma situação da qual pode ser libertado. A escola, ainda que revele falta de sintonia com o mundo jovem, é o local indicado para auxiliá-lo nesse processo.

Quanto à mídia e escola, os trabalhos teóricos propóem reflexóes sobre a inter-relação entre os campos da Comunicação e da Educação. Outra discussão presente envolve a inserção da educação para a mídia no currículo escolar, seja como disciplina autônoma ou integrando o currículo transversal.

Como na ANPEd, a escola aparece como espaço genérico no qual a educaçáo ocorre. Sáo poucos textos que delimitam níveis específicos de ensino, e os que o fazem são, em geral, trabalhos empíricos. Há menção a atividades desenvolvidas desde a educação infantil até a educação de jovens e adultos.

Grande parte das pesquisas acontece na escola, motivada por diversos anseios: observar processos de recepção midiática; entender a opinião e a relação dos docentes e jovens com as mídias, dentro e fora dos muros escolares; desenvolver experiências com produção de textos midiáticos; averiguar dos benefícios que as TIC trazem para o processo ensino-aprendizagem.

Problemas como o descompasso existente entre os objetivos da instituição escolar e os interesses dos estudantes, a ineficiência e a obsolescência da escola são trazidos à tona pela maior parte dos pesquisadores. Fragilidades estruturais - como os jogos de poder e suas relaçóes de dependência e submissão, baixos salários e a falta de motivação dos professores, a carência de pessoal técnico nas unidades escolares, a excessiva burocracia, a limitação dos sistemas de controle e supervisão, a falta de suporte pedagógico comprometido com a eficiência do processo de ensino-aprendizagem - raramente permeiam as consideraçóes. 
Estão presentes temas transversais que visam à educação para: o consumo consciente, envolvendo textos do gênero publicitário, como resposta à exposição precoce das crianças à publicidade televisiva; o desenvolvimento da consciência ambiental; a educação sexual, como forma de responder a diversos questionamentos dos alunos; a relação entre a exposição aos textos midiáticos e o declínio do interesse da leitura de textos impressos pelos estudantes. Alguns trabalhos ocupam-se da análise de propostas educativas formuladas por atores não escolares, como ocorre com os projetos Veja na Escola, da Editora Abril, e Jornal na Educação, da Associação Nacional de Jornalismo.

A metodologia é objeto de discussão em muitos textos. Há críticas a uma suposta "pedagogia tradicional", indicando-se a necessidade de mudança nas aulas, de se realizar e de se avaliar atividades, dando ênfase à transdisciplinaridade, ao trabalho com a emoção e a arte. Entre as metodologias sugeridas estáo a pedagogia de projetos, a leitura crítica e a comunicação crítica, que permitam aos estudantes expressar-se, produzindo textos midiáticos. Em parcela dos trabalhos, defende-se o uso combinado da mídia e da tecnologia como recurso didático e como objeto de estudo e espera-se que essa utilização seja atrelada aos conteúdos curriculares. Os resultados almejados são a motivação, a participação ativa, a interação entre os estudantes, com negociações de sentido para o aprendizado de conteúdos curriculares e de temas transversais, o exercício da cidadania, a formação e a consolidação de valores, o fortalecimento das relaçóes sociais, o protagonismo jovem, o rompimento da hierarquização do poder na escola.

Nos trabalhos da Intercom, nota-se especial preocupação com as características das linguagens midiáticas. Diversos trabalhos ocupam-se das especificidades das linguagens: visual - enfocando a TV aberta, o potencial da TV digital, o cinema, a fotografia; virtual - a internet, o game, redes sociais; impressa - jornal e revista; e sonora - rádio, música.

\section{CONSIDERAÇÓES FINAIS}

Não há divergências essenciais no percurso dos dois eventos, quanto à percepção da interface Educação e Comunicação. Os grupos compartilham pressupostos teóricos, o que produz consonância entre as preocupações mantidas e as propostas formuladas, bem como o reconhecimento da centralidade da instituição escolar e dos educadores para a validaçáo das propostas. No que tange à educação para a mídia, destaca-se a ênfase dada à discussão sobre a própria identidade do campo de saber.

Os resultados apresentam predominância de pesquisadores do eixo sul-sudeste. Os programas de pós-graduação das universidades dessas regiôes encontramse mais consolidados. Tal fato soma-se ao pioneirismo na abordagem da temática na ECA/USP, responsável pela formação de grande parcela dos pesquisadores.

A escola é o lugar privilegiado para todos os pesquisadores. $\mathrm{Na}$ Intercom, no entanto, o percentual de pesquisas realizadas fora da escola revela-se discretamente maior do que na ANPEd, o que pode ser justificado pela tradição histórica dos estudos sobre comunicação comunitária. A escola é percebida de diferentes maneiras: a) espaço de mediação entre a criança e a sociedade, visando à construção da cidadania; b) lócus do saber formal, onde mais se procura transmitir do que produzir conhecimento; c) microcosmo social, comunidade com identidade e valores próprios em que um ecossistema comunicativo faz a diferença. Ela é, com muita frequência, posicionada nos textos como sendo um entre os diversos agen- 
tes de socialização, categoria igualmente ocupada pela escola paralela: a mídia. $\mathrm{O}$ apelo frequente dos pesquisadores diz respeito à ressignificação da instituição escolar, propondo uma revisão em suas práticas e conteúdos, para assegurar que o aluno se aproprie da realidade social de forma crítica, estruturando, organizando e reorganizando sua percepção de mundo, bem como se preparando para o mercado de trabalho.

Nos dois eventos, a grande maioria dos estudos preocupa-se com a apropriação das tecnologias na educação que favoreça a comunicação dialógica e permita a leitura crítica de textos midiáticos. Ao longo da década analisada percebese gradual distanciamento da atitude de oposição à entrada da tecnologia na escola, dando espaço a estudos críticos sobre os aspectos políticos e culturais da relação sociedade, escola e tecnologia e, finalmente, a pesquisas preocupadas com o preparo para a inevitável inserção das mesmas na educação. No entanto, todas essas perspectivas convivem nas mais diversas ediçóes desses eventos, caracterizando um período de diferentes posicionamentos frente à submissão do homem à tecnologia. Nos últimos anos há incremento no relato de experiências aplicadas com a intenção de verificação de metodologias para o trabalho com a tecnologia e a mídia na escola, incluindo a utilização da tecnologia para o ensino a distância.

Em relação à educação para a mídia é digna de menção a influência do grupo de pesquisa da ECA/USP sobre os trabalhos estudados nos dois eventos, nos quais é possível registrar o uso do termo "educomunicação", proposto por eles, para identificar a área de intervenção educativa.

\section{REFERÊNCIAS BIBLIOGRÁFICAS}

BRASIL. Secretaria de Educação a Distância. Disponível em: <http://bit.ly/ lvZoEB>. Acesso em: 03 maio 2011.

CITELLI, A.O. "Comunicação e educação: reflexôes sobre uma pesquisa envolvendo formação de professores". Disponível em:< http://bit.ly/kMJmqG >. Acesso em: 01 maio 2011.

COSTA, B.C.G. "Ambiente das mídias digitais: reflexôes sobre comunicação e Educação". PERSPECTIVA, Florianópolis, v. 27, n. 1, 141-164, jan./jun. 2009. Disponível em: < http://www.perspectiva.ufsc.br >. Acesso em: 17 abr. 2011.

INTERCOM. Comunicação e Educação (DT 6). 2008. Disponível em: <http:// www.intercom.org.br/pesquisa/gps/educativa.shtml >. Acesso em: 17 abr. 2011.

MOSTAFA, S.P.; MAXIMO, L.F. A produção científica da ANPEd e da Intercom no GT da Educação e Comunicação. Ci. Inf., Brasília, v. 32, n. 1, Apr. 2003. Disponível em: < http://bit.ly/jLZDLu >. Acesso em: 18 abr. 2011. doi: 10.1590/S0100-19652003000100010. 